\title{
5 Bifeminist anti-monogamy and the politics of erotic autonomy
}

\author{
Christian Klesse
}

\section{Introduction: Anti-monogamy critiques in feminism}

The critique of monogamy has been a pervasive feature of feminist debates on gender, power, and sexuality since the nineteenth century. Different currents within feminist theorising and activism have tackled the oppressive effects of cultures of sex, intimacy, and kinship that render monogamy a normative feature within women's lives. Rejections of monogamy were voiced from within Marxist and anarchist feminism in the late nineteenth and early twentieth centuries, in existentialist feminism in the postWorld War II years, and in various strands of radical feminism, lesbian feminism, and bisexual feminism since the late 1960s, unfolding in a complex genealogy that extends to contemporary queer-feminist positions.

This work has developed different foci, ranging from critiques of capitalist gender relations and the division of labour over attempts to reshape female subjectivity to hetero-patriarchal constructions of love and the family. Some of this work has also been motivated by sexual liberationist ideas or identity political agendas (for example, as in radical feminist, lesbian feminist, or bifeminist movements). Despite important differences, I suggest that all these lineages are interconnected and held together by common threads of discourse. One of the unifying features of feminist anti-monogamy has been the common concern with women's erotic autonomy. Yet how the concept of autonomy has been filled with meaning depends profoundly on the backdrop of the respective wider social movement agendas.

While I have documented the breadth of this genealogy of feminist antimonogamy critiques elsewhere (Klesse, 2018), I focus here specifically on bifeminist refutations of monogamy, concentrating primarily on work published in the United States and United Kingdom in the 1980s and 1990s, with the aim of highlighting arguments that have influenced more recent bisexual and queer feminist discussions on the topic. Through the analysis of some key texts, I show that bifeminist critiques of this period have shared some of the core assumptions prevalent within other identity-related feminist currents (such as lesbian feminism and heterosexual feminism), while endorsing a bifeminist standpoint and advocating a distinctly bifeminist 
ethics of erotic autonomy at the same time. These positions have fed into more recent queer feminist discussions. Yet, as I will show at the end of this article, tensions between bisexual (feminist) and queer (feminist) forms of theorising persist. Before turning to the analysis of some selected key texts, it appears to be necessary to briefly sketch the historical debates on autonomy. ${ }^{1}$

\section{Feminist debates on autonomy}

The value of the concept of autonomy as a mobilising tool for empowerment has been contested across different strands of feminist philosophy. Some feminists have rejected the idea of autonomy as being implicitly androcentric, operating within a reductionist liberal framework that focuses on the individual, who is conceived as a self-governing subject bare of care relations and dependencies.

Distinct critiques of autonomy have been guided by a wide range of theoretical perspectives, including psychoanalysis (namely object relations approaches to gender identity), Lacanian critiques of coherent subjectivity, Foucault-inspired attacks on the rational Enlightenment actor, refutations of liberal contract theory from within critical theory, Marxist and materialist critiques of care work, and intersectionality theories derived from within Black feminism.

I concur with Mackenzie and Stoljar (1999, p. 3) that while these feminist critiques of autonomy have identified serious theoretical and political problems with some historical and contemporary conceptions of autonomy, the notion of autonomy is vital to feminist attempts to understand oppression, subjection, and agency.

In recent years, we have witnessed a critical reappraisal of the concept of autonomy in feminist philosophy. Many feminist scholars are adamant that some notion of autonomy needs to be retained in order to theoretically conceive of agency, personal change, or collective social struggle (Friedman, 2003; McNay, 2000). They refute the charge that the notion of autonomy is necessarily individualistic and foreground the "relational" dimensions within certain conceptualisations of autonomy that highlight the interconnection between subjects and their networks and social environments, and their embeddedness in structures of constraint (Friedman, 2014; Mackenzie, 2014; Veltman \& Piper, 2014). Many contributors to these debates do not engage with questions of sexuality. Although feminist discussions of nonmonogamy rarely take account of these more abstract debates in feminist philosophy, I hold the view that it is helpful to read these literatures alongside each other because they share common concerns.

\section{Bisexual feminism and the critique of monogamy}

Feminist activists, including bisexual feminists, have converged in the belief that the common conflation between bisexuality and non-monogamy (as a 
bisexual default condition) poses a problem for bisexual politics (Monro, 2015 ). That notwithstanding, research indicates that the relationship values, cultural identifications, and positions within bisexual communities with regard to sexual politics are highly diverse (Queen, 1995). For different reasons, many bisexual-identified people feel drawn to and consciously opt for non-monogamous or polyamorous ways of life (Klesse, 2005; Robinson, 2013; Rodriguez Rust, 2000). Moreover, research suggests that for many bisexual women, their non-monogamy is infused with a commitment to feminism, gender equality, or female empowerment, or their opposition to hetero-patriarchal gender regimes (Deri, 2015; Ritchie \& Barker, 2007).

In this chapter, I look in closer detail at how bisexual feminists have discussed bisexual nonmonogamy and polyamory as articulations of erotic autonomy and strategies of resistance. I critically analyse key publications from the 1980s onwards that criticise monogamy from a bisexual perspective.

It is important to remember that the rejection of monogamy was a quite common feature in 1970s and 1980s militant feminism, spanning different ideological currents from radical to Marxist feminism, with distinctive articulations among women who were seen as minorities (Jackson \& Scott, 2003). Feminist attacks on compulsive monogamy rejected hetero-patriarchal marriage as a socio-legal institution that subordinated and disenfranchised women, sustaining an emotional culture of exploitative gender relations (Willey, 2016; see also Comer, 1974). Ideas of sexual liberationism were another major ideological influence that pervaded many counter-cultural milieux, including certain feminist activist circles (Campbell, 1974). Bisexual feminist thought has been built upon these legacies, and both ideological currents can be identified in bi feminist work of the 1980s and 1990s.

Hemmings (2002) argues that bisexual perspectives tend to emerge at the conjunctures of dominant frameworks of sexual classification. Bisexual feminism has formed a kind of third space - in the sense given to the term by Bhabha (1990) - which allows for hybrid rearticulations of experiences and conceptual frameworks. Hemmings pays particular attention to the dialogue between bisexual feminism and lesbian feminism, arguing that bisexual feminism has been shaped in constant friction and interaction with lesbian feminism. This was particularly so during the period of feminist politics in which lesbian feminism assumed a strong, if not a hegemonic, position within radical feminism.

A further reason for the prominence of a lesbian feminism as a point of reference for bisexual feminists in this period was that at least in some countries, particularly the United States, many bisexual feminist leaders had previous experience of organising within lesbian feminist politics (Udis-Kessler, 1996). Moreover, the very term "bisexual feminism" had been contentious from the point of view of a lesbian feminist position that endorsed political strategies of separatism, at the level of both political organisation and personal relationships. The edited volume Closer to Home. Bisexuality and Feminism (Weise, 1992) elaborates how bisexual feminism was caught up 
between the forces of "heterosexual sexism and the ideological purity of the lesbian community". From the late 1960s to the 1990s, many lesbian feminists engaged in a hostile discourse against bisexual feminism, partly as a result of widely held popular anti-bisexual sentiments, and partially in response to the specific challenges posed by bisexual feminism to the central tenets of lesbian feminist ideology and the destabilising effects it had with regard to lesbian identity narratives and rationalities of community formation (e.g. Jeffreys, 1999; see Ault, 1994 for a critical analysis).

George (1993, p. 46) remembers:

For some years in the 1970s and 1980s it was very difficult for an active feminist to be open about her bisexuality. For many feminists, bisexuality was seen simply as the cowardly holding to heterosexual privilege.

While in the United Kingdom anti-bisexual sentiment in lesbian communities was mostly rather subtle, lesbian feminists in the United States contested bisexuality in heated public arguments. For all these reasons, bisexual feminists were engaged in a close engagement with debates in lesbian feminism. In the following section, I argue that bisexual discourses on nonmonogamy developed through a careful reworking of lesbian feminist ideas on anti-monogamy.

\section{Political lesbianism, women's communities, and the "dyke-ethics of anti-monogamy"}

Against the common stereotype of lesbian feminism being bound up with a corporeal culture of prudery, lesbian feminists were probably the most vocal critics of monogamy, which often was dismissed as a remnant of "compulsive heterosexuality" (Wandrei, 2019). For many lesbian feminists, monogamy, marriage, and the subordination of women are seen as inherently linked (Stelboum, 1999).

In a contribution to a volume of UK feminist activist writing, Becky Rosa (1994) suggests that non-monogamy can be conducive to lesbian feminist autonomy by responding in flexible and non-assimilationist ways to women's relationship needs and by supporting the collective strength of women through the creation of friendship-based women's communities. Angela Willey (2016) sees Rosa's argument as a formulation of a transformative "dyke ethics of anti-monogamy".

The emphasis on a feminist ethics of friendship is closely linked to the broadening of the category "lesbian" through a fusion of feminism with lesbianism and the refashioning of lesbian identity away from sexual orientation to a primarily political identity (around women-centred life choices and political strategies) since the 1970s. Rich (1983) bemoans the social pressures and sanctions that force women into heterosexual relationships. 
She aims to counteract the culture of heterosexism through the promotion of a "woman-identified" culture of relationality, suggesting that all women could place themselves on a lesbian continuum if they decided to forsake relationships with men in favour of close, intimate bonds with women. Although Rich does not explicitly endorse non-monogamy, monogamy itself is cast as an integral element of heteropatriarchal culture to isolate women from each other and to subject them to the control of individual men (husbands) (Stelboum, 1999).

Rosa's (1994) influential article “Anti-monogamy: A Radical Challenge to Compulsory Heterosexuality" elaborates these common views within political lesbianism and cultural feminism into a distinctively political anti-monogamy stance. This article is considered to be emblematic of the approach to non-monogamy within lesbian feminism in this period by Willey (2016). It is noteworthy that in this text monogamy is not simply seen as a way of regulating individual women's sexuality; rather, it defines a more comprehensive couple-focused social imaginary (Rosa, 1994). Rosa (1994, p. 109) argues that, "For monogamy to exist, there needs to be a division between sexual/romantic love and nonsexual love". This distinction implies the denigration and underrating of friendship bonds. In particular, this aspect reveals the pervasive and far-reaching powers of monogamy as a regulative ideal. It is because of the wider value system articulated within compulsive monogamy that, "Women's monogamy has repercussions for their friends, for nonmonogamous women, and for feminism" (Rosa 1994, p. 108).

An enhanced scope for autonomy is a core value in Rosa's appreciation of friendship: "Friendship is more compatible with autonomy, independence and freedom, and perhaps has a more voluntary nature than the obligation of love relationships" (Rosa 1994, p. 112). Rosa states clearly that her concern is not so much sexual liberation, but the creation of a feeling of community among women. By distinguishing her project of anti-monogamy from casual sex by linking it to long-term commitments, Rosa engages in a discourse that strongly resonates with contemporary debates on polyamory.

It should be noted that more liberationist discourses on lesbian women's sexuality also circulated in lesbian communities in this period (Wandrei, 2019). In the United States, sex-positive positions can be identified, for example, in the writings of Rubin (1992) or Duggan (1995). The sex-positive discourse on lesbian sexuality gained a stronger profile in the course of the so-called sex wars (Walters, 2016). It can be seen as a precursor of queer theory. After having mapped core arguments in lesbian feminist debates on non-monogamy in the 1980s and 1990s, I proceed to show how bisexual feminist positions of the time mirror and differ from these positions. With all their differences, they share an investment in what could be called a bifeminist ethics of non-monogamy, cast as a concern with women's erotic autonomy. 


\section{Bi feminism/lesbian feminism: Solidarity and tension}

Many bisexual feminists refer very positively to Rich's critique of heteropatriarchy and her political project of creating woman-identified networks and culture, even if they struggle with the concept of the "lesbian continuum" due to its implicit erasure of bisexual identification (Bennett, 1992; Kaplan, 1992).

Bennett (1992, p. 222) challenges Rich's "assertion that all women who desire connection with other women are truly lesbian", which she reads as a quasi-essentialist statement. Asserting that, "For many bisexual women, woman-identification is a crucial part of our experience" (Bennett, 1992, p. 222), she inscribes bisexuality into women-centred visions of sociality.

In the same edited volume, Kaplan (1992) engages in a close reading of Rich's (1983) canonical article "Compulsory Heterosexuality and Lesbian Existence." Like Rich, she condemns the "unexamined heterocentricity" that structures many women's lives (Kaplan, 1992, p. 270) and she questions the privilege that women may derive from having intimate relationships with heterosexual men. At the same time, she is wary of Rich's implicit determinism, the expansive definition of lesbianism, and Rich's refusal to directly address the question of bisexuality in a meaningful engagement. She questions the generalised categorisation of woman-oriented acts as resistance. Finally, she offers a reading of Rich's ideas of resistance to compulsory heterosexuality that highlights reflexive struggle rather than withdrawal. Rich's major argument, she states, has been with the lack of choice women have with regard to their gendered partnering options and not with the fact that some women live heterosexual lives:

The quest is not necessarily for women to abandon relationships with men, but rather, to be free from requirements to be with men and to be self-conscious of our motivations when we are with men.

(Kaplan, 1992, p. 275)

This argument entails a quest of women's autonomy, with regard to both heteronormative and lesbian community-focused normative expectations. It is based on a principled stance against patriarchy and endorsement of woman-centred life choices:

Both acts that are pro-woman and acts that assert women's independence from men can be ways to resist a heteropatriarchal imperative which posits as the focus of women's existence.

(Kaplan, 1992, p. 272)

This sentiment was widely shared among bisexual feminists in the United States in this period (see also Baker, 1992; Elliott, 1992; Udis-Kessler, 1992). 
In an article published in the United Kingdom, Gregory (1983, p. 140) speaks about the desire "to put forward a notion of woman-centred sexuality which would unite lesbian, heterosexual and bisexual women, and which would include celibate women". This position, too, mirrors the emphasis on friendship and community among women proposed by lesbian feminist activists. Yet while lesbian feminists believed that the label "lesbian" or the notion of the "lesbian continuum" could serve as a suitable umbrella term to signify this community spirit, bisexual feminists like Gregory continue to name differences in term of identity and construe unity as the result of proactive alliance-building. Arguments about mutual solidarity and coalition work that acknowledge both unity and difference were common in 1990s bisexual feminism (George, 1993).

While there are overlaps of lesbian and bi feminist discussions of nonmonogamy, bifeminist positions at times differ quite profoundly from lesbian feminist criticism. This is because many advocates of political lesbianism were adamant that true feminists should stop having sexual relationships with men.

Whereas some bisexual feminists argued that non-monogamy with partners of different genders could render bisexual women's identities visible and tangible (Gregory, 1983; Murray, 1995), and therefore would be a valid strategy in the larger project of bisexual women's feminist empowerment, at least some currents within lesbian feminism pronounced that romantic or sexual contacts with men would inevitably erase a woman's legitimacy to access the very category "feminist".

In the United Kingdom, the Leeds Revolutionary Feminist Group (1981, p. 8) proclaimed, "Giving up fucking for a feminist is about taking your politics seriously”. Intimate and/or sexual relationships with men were frowned upon, since they directed energy and care to the class of oppressors. Women were expected to prove their commitment to women's resistance and womenidentified culture by entering relationships with women or being celibate. Both heterosexuality and bisexuality appeared to be politically suspect from within this position. Often bisexual women were specifically singled out for attacks (Jeffreys, 1999). Similar discourses prevailed in the United States (George, 1993; Udis-Kessler, 1992).

It is not surprising, then, that although many bisexual and heterosexual feminists shared the critique of marriage, institutionalised heterosexuality, and compulsory monogamy with lesbian feminists, they defined erotic autonomy in ways that explicitly defended in political terms nonmonogamous relationship choices that may include men (at least as an hypothetical option) (Gregory, 1983; Murray, 1995; Robinson, 1997). The claim to a right to engage in romantic or sexual relations with people of different genders is key to bifeminist treatments of the non-monogamy question in this period. 


\section{Individual choice, bisexual freedom, bisexual autonomy}

For bisexual feminists, the envisioned unification of and mutual solidarity among different groups of women and different factions of feminism can only be possible if women's choices to have sexual and/or intimate partners were considered as being in principle legitimate. Many bi feminist critiques of non-monogamy therefore tend to highlight the individual woman's right to love whomever she decides to love (Elliott, 1992). Kaplan (1992, p. 269), for example, argues:

One of the underlying principles in a bisexual-feminist ideology is that of sexual choice. The primary focus is on the right to choose male and female lovers, ${ }^{2}$ but the concept of sexual choice can be expanded to include other issues, such as the right to choose nonmonogamy, to choose lovers of traditionally 'inappropriate' socio-cultural groups and to choose not to have sex.

Autonomy is here articulated in the terms of rights and presented as a matter of choice, in a codification that strongly resonates with Plummer's (1995, p. 151) notion of intimate citizenship, which contains "socially grounded choices (or not) about identities, gender experiences, erotic experiences" as a core element of its definition (emphasis in original).

Gregory (1983), too, puts an emphasis on bi women's individual autonomy, but with a slightly different slant, suggesting that bisexual integrity can only be sustained by a form of autonomy that commands emotional containment (or emotional celibacy). Whatever a bisexual woman's relationship status may be, she argues, there is an element within bi eroticism that prevents bisexual women from completely identifying with their lovers. "When we consciously embrace our sexuality, we affirm that our full individual sexuality can only exist in so far as we locate it within ourselves" (Gregory, 1983, p. 151). This is why Gregory (1983, p. 150) suggests that bisexuality has an "in-built potential for personal autonomy". Put differently, "Bisexuality implies a fundamental separation of ourselves from all our relationships. It implies that our sense of sexual definition and personal fulfilment can never come through any one sexual relationship" (Gregory, 1983, p. 153).

Gregory detaches her argument for self-ownership from the question of relationship status (and thus the practice of non-monogamy) by framing her concern with erotic autonomy as a question of selfhood and bisexual authenticity bound up with the personal capacity for nonmonogamy.

\section{Systemic critique and bi standpoint logic}

Murray (1995, p. 293) presents a principled political critique of compulsory monogamy from "an explicitly bifeminist standpoint". The text doesn't just highlight the empowering and transgressive potential of women's 
non-monogamous relationship choices, it also articulates an appeal to the bisexual community - and to bifeminists in particular - to defend nonmonogamy as a valid way of life and to collectively struggle against compulsive monogamy.

Murray's (1995) discussion contains many threads that are common across different currents of feminist monogamy critique from the 1970 into the 1990s - for example, the rejection of the gendered double standard, slut shaming, and the emotional and physical control of women in heteropatriarchal marriage. Non-monogamy is often associated with the word "promiscuity" in ways that reveal a fear of pro-sex attitudes and sexual motives. This amounts to a call for solidarity based on a vision of an erotically diverse bisexual community, similar to Queen's (1995) plea, published in the same volume of bisexual writing as Murray's (1995) chapter.

Let me illustrate these features in somewhat more detail. Murray's (1995) chapter opens with a rigid refutation of compulsory monogamy. The second paragraph reads, "A bisexual politic rooted in feminism must examine issues such as monogamy head-on, rather than dance defensively around controversial questions". (Murray, 1995, p. 293). She complains that "many monogamous bisexual feminists try to downplay the presence of nonmonogamy in bi women's communities" (Murray, 1995, p. 302).

\section{The autonomy of choice: Between structuralism, contract law, and market logic}

Murray (1995) clearly addresses monogamy as a structural or an "institutionalised" social formation. Its institutional character is revealed on several levels: On the most basic level, monogamy is naturalised, i.e. represented as a cultural norm as if it was "the 'natural' way we form relationships" (1995, p. 295). Monogamy is further kept in place through a contractual logic. While Murray discusses the marriage contract (both as an interpersonal arrangement and a wider social imaginary), she also refers to other models of contract. It is interesting that Murray also evokes labour law to discuss the particularities and oddities of monogamous arrangements:

Monogamy is one of the few contracts in which relations with other parties are relevant to the partnership. If your company doesn't want you working for anybody else, it must state this exclusivity specifically in your contract. Otherwise, you can assume it is acceptable to take jobs with other employers too (though not on company time, of course). I find it strange that in sexual relationships, the exclusive arrangement is the marked case.

(Murray, 1995, p. 295)

The casual - and, I would argue, non-reflexive - way in which labour market rationalities are introduced to highlight discourses and emotional schemes 
around non-monogamy reveals the strong extent to which Murray's discussion remains steeped in a liberal capitalist and market individualism. Labour and business law, and conceptual reasoning, provide the templates through which relationship dynamics are read and interpreted. The employment contract is here represented as an agreement between individuals framed as rational subjects, delineating their mutual commitments bare of concerns with power differentials and structural constraints.

Murray's critique of monogamous marriage is articulated within a more structural critique of contract thinking. She sees marriage as a system of control and privilege that operates through a model of property rights (based on exclusive ownership of access to women's bodies, labour, and offspring). Murray (1995) further highlights the protections for women that come along with marriage arrangements and that many perceive as a benefit. Non-monogamous women threaten these cultural customs and dealings. Very much in the spirit of Goldman's (1897) and de Beauvoir's (1949/1976) critique of marriage, Murray sees such protective solutions as destructive of women's spirit of independence. This dynamic reveals the contradiction between women's autonomy and monogamy: "After all, monogamy contradicts the feminist goal of women's control of their own bodies and decisions about their own agency" (Murray, 1995, p. 297).

The contract of monogamy further shores up identities, gendered subject positions, social conventions, notions of property, and the status quo by the creation of "safe" categories of people. In contradistinction, "Nonmonogamous bisexuality forces people to make active, conscious decisions about when and whether to become sexual with someone" (Murray, 1995, p. 298). This calls into question taken-for-granted boundaries of "relationships", "friendships", and the gendered codes in which they are presented. This bifeminist ethics of anti-monogamy thus enhances (self-) reflexivity and increases personal autonomy.

Furthermore, according to Murray (1995), non-monogamous bifeminism helps to create critical gender knowledge on an experiential level. Erotic engagement with people of different genders allows unique and potentially transgressive insights into the gender order. While Murray's definition of bisexuality largely follows a binary logic, her arguments about experimental exploration emphasise boundary blurring in a more queer fashion.

\section{Queer (bi)feminist theory: Queering gender - queering sexuality}

(Bi)feminist critiques of monogamy that follow the epistemological or queertheoretical turn in bisexual theory (Alexander \& Anderlini'Onofrio, 2012) are critical of all kinds of essentialism and argue that bisexual nonmonogamy carries a deconstructive potential with regard to normative ideas concerning intimacy, gender, and sexual identity (Baker, 1992).

For example, Gustavson (2012) argues that a queer bisexual perspective allows movement from a model of sexual orientation that relates to gender 
in terms of object choice to an understanding that looks at relationship practice in a more dynamic fashion. If we pay attention to the fluidity at the heart of ordinary stories of eroticism in everyday life, it is possible to avoid the gender binary at the heart of dominant sexual ontologies. Bisexuality provides a promising vantage point from which to critically undo such traps in representing human desire or the body because it does not hinge upon the question of sexual object choice. "Bisexuality differs from (modern) notions on homosexuality and heterosexuality, because these are defined by the expected gender of the partner" (Gustavson, 2012, p. 216). This is the case because

bisexuality avoids this definition because it indicates that the object of desire may shift, and gender as an object choice is therefore not central to sexual identity. It would be pointless to try to decide the gender of the partner by knowing that a person is bisexual.

(Gustavson, 2012, pp. 215-16)

Bisexuality thus creates gender trouble, because within bisexual scenarios of attraction and desire, object choices cannot be matched onto each other as Butler's analysis of the heterosexual matrix would imply (see Hemmings, 2002; see also Callis, 2009).

Many bisexual feminists suggest that bisexual non-monogamy tends to subvert gender and sexual orientation binaries due to its inherent complexity and fluidity (Barker, 2005; Gurevich, Bailey, \& Bower, 2009). This literature resonates with a view of "bisexuality beyond gender", or at least bisexuality beyond gender duality, which has been widely embraced in queer-infused bisexual theory (Eisner, 2013) and has gained stronger ground within bisexual politics over recent years (Bowes-Catton, 2007).

The relationship between bisexual theory and queer theory or poststructuralist feminism is a complicated and ambivalent one. Many bisexual activists and theorists initially endorsed queer theory as a beacon of hope for bisexual inclusion (Burrill, 2002), but were quickly disappointed by the lack of consideration paid to bisexuality by key theorists, such as Eve Kosovsky Sedgwick, Diane Fuss, and Judith Butler (Young, 1997). Many believe that a bisexual perspective would be compatible with and conducive of a radically inclusive politics with a queer deconstructive agenda (Callis, 2009; Hemmings, 2002). "Inasmuch as bisexuality poses a threat to the institutions of heterosexuality and homosexuality, it also opens up a set of truly queer possibilities", argue Erickson-Schroth and Mitchell (2009, p. 313). Similarly, Callis $(2009$, p. 230) hopes that, "The melding of the two [queer and bisexual theories] will allow queer theory to strengthen its position of deconstruction, while forcing bisexuality to remain openly identified and inclusive". Others, while being overtly sympathetic to queer theoretical and poststructuralist feminist approaches, have also stressed the risk of subjecting an already precarious category such as bisexuality to deconstruction (Monro, 2015). 
Many of the arguments discussed here mirror concerns raised in the longstanding debates between feminism and queer theory at large (Richardson, McLaughlin, \& Casey, 2006). Yet bisexual feminists feel that the common devalidation of bisexual identities exacerbated the risks of depoliticisation, delegitimation, and invisibility long before bisexuality ever has been granted any recognition whatsoever. Queer feminist bisexual critiques of monogamy have therefore mostly continued to highlight bisexual specificity. Bifeminist anti-monogamy - even within a deconstructive framework - thus contains a politics of erotic autonomy that is committed to a distinctive subjectivity, whether articulated as a sense of self, an endorsement of capacity, a communal imaginary, or a socio-political project.

\section{Conclusion: Queer feminist nonmonogamy - queering women's bonds through autonomy}

In this chapter, I have shown that bisexual feminist critiques of monogamy since the 1980s and 1990s have tended to endorse the value of women's erotic autonomy and agency through a focus on women as desiring subjects. The concrete terms of the definition of autonomy depend on historical context, political constellation, and the wider theoretical frameworks deployed in the social movement currents within which they were developed. Distinctive perspectives of autonomy have been guided by the critique of marriage and patriarchy, to endorsements of women's communities, the proclamation of personal freedom and choice, the discourse of identity and authenticity, the rejection of privileges bound up with fulfilling the normative expectations to be monogamous, and the transgression of gender norms, sexualities, and relational categories. Originally strongly tied to bisexual standpoint rationalities, concerns with identity recede into the background as time progresses. As the discussion moves from the 1980s into the 1990s and into the new millennium, queer feminist arguments about deconstruction, binary critique, and gender trouble become more vocal. Yet most bisexual feminists continue to insist on highlighting bisexual difference and specificity in order to avoid queer theory becoming yet another driver for bi erasure, a dynamic so well described by Yoshino (2000).

\section{Notes}

1 In this article, I use the terms "bifeminism" or "bisexual feminism" interchangeably. Both terms are used in the literature. I reserve these terms for work that has been published under this label or that deals with gender inequalities in contexts clearly defined as bisexual. I highlight ambiguities around positioning wherever this is appropriate. For this article, I worked with more than 30 texts in English language from different countries (notably the United States and the United Kingdom) that explore bisexuality and non-monogamy from women's or gendercritical perspectives, presenting or developing arguments that resonate with the 
discursive repertoires of feminism. Due to restrictions in terms of word length, not all these works can be cited in this article. I decided to focus on work that has been influential for activist debates (such as articles published in popular anthologies) or that is more theoretical in nature (compared with work that reports research findings). As always, the boundaries between different genres of texts are fuzzy and cannot always be drawn easily.

2 Nowadays, most bisexual feminists would use a different language to define bisexuality that is more attentive to the problems of gender-dualistic constructions See Bowes-Catton (2007) and Eisner (2013) for a discussion of contemporary meanings of bisexuality within queer and trans* epistemologies.

\section{References}

Alexander, J., \& Anderlini-D’Onofrio, S. (2012). Bisexuality and queer theory. Intersections, connections and challenges. London: Routledge.

Ault, A. (1994). Hegemonic discourse in an oppositional community: Lesbian feminists and bisexuality. Critical Sociology, 20(3), 107-22. doi: 10.1177/ 089692059402000306

Baker, K. (1992). Bisexual feminist politics: Because bisexuality is not enough. In E.R. Weise (Ed.), Closer to home: Bisexuality and feminism, (pp. 255-67). Seattle, WA: Seal Press.

Barker, M. (2005). This is my partner, and this is my ... partner's partner: Constructing a polyamorous identity in a monogamous world. Journal of Constructivist Psychology, 18(1), 75-88. doi: 10.1080/10720530590523107

Beauvoir, S. (1949/1976). The second sex, trans. H.M. Parshley. Harmondsworth: Penguin.

Bennett, K. (1992). Feminist bisexuality: A both/and option for an either/or world. In E.R. Weise (Ed.), Closer to home: Bisexuality and feminism (pp. 205-31). Seattle, WA: Seal Press.

Bhabha, H.K. (1990). The third space. In J. Rutherford (Ed.), Identity, culture, difference (pp. 207-21). London: Lawrence and Wishart.

Bowes-Catton, H. (2007). Resisting the binary: Discourses of identity and diversity in bisexual politics 1988-1996. Lesbian and Gay Psychology, 8(1), 58-70.

Burrill, K. (2002). Queering bisexuality. Journal of Bisexuality, 2(2/3), 95-105. doi: 10.1300/J159v02n02_06

Callis, A.S. (2009). Playing with Butler and Foucault: Bisexuality and queer theory. Journal of Bisexuality, 9(3-4), 213-33. doi: 10.1080/15299710903316513

Campbell, B. (1974). Sexuality and submission. In S. Allen, L. Sanders, \& J. Wallis (Eds.), Conditions of illusion: Papers from the women's movement (pp. 99-109). London: Feminist Books.

Comer, L. (1974). Wedlocked women. London: Feminist Books.

Deri, J. (2015). Love's refraction. Jealousy and compersion in queer women's polyamorous relationships. Toronto, CA: University of Toronto Press.

Duggan, L. (1995). Introduction. In L. Duggan, \& N.D. Hunter (Eds.), Sex wars (pp. 1-14). London: Routledge.

Eisner, S. (2013). Bi notes for a bisexual revolution. Seattle, WA: Seal Press.

Elliott, B. (1992). Holly near and yet so far. In E.R. Weise (Ed.), Closer to home: Bisexuality and feminism (pp. 233-254). Seattle, WA: Seal Press. 
Erickson-Schroth, L., \& Mitchell, J. (2009). Queering queer theory, or why bisexuality matters. Journal of Bisexuality 9(3-4), 297-315. doi: 10.1080/ 15299710903316596

Friedman, M. (2003). Autonomy, gender, politics. New York: Oxford University Press. Friedman, M. (2014). Relational autonomy and independence. In A. Veltman \& M. Piper (Eds.), Autonomy, oppression, and gender (pp. 61-86). New York: Oxford University Press.

George, S. (1993). Women and bisexuality. London: Scarlet Press.

Goldman, E. (1897). Marriage. The Firebrand, 3(24), 2.

Gregory, D. (1983). From where I stand: A case for feminist bisexuality. In S. Cartledge, \& J. Ryan (Eds.), Sex and love: New thoughts and old contradictions (pp. 14156). London: The Women's Press.

Gurevich, M., Bailey, H., \& Bower, J. (2009). Querying theory and politics: The epistemic (dis)location of bisexuality within queer theory. Journal of Bisexuality, 9(3): 235-257. doi: 10.1080/15299710903316539

Gustavson, M. (2012). Bisexuals in relationships: Uncoupling intimacy from gender ontology. In J. Alexander, \& S. Anderlini-D’Onofrio (Eds.), Bisexuality and queer theory. Intersections, connections and challenges (pp. 215-38). London: Routledge.

Hemmings, C. (2002). Bisexual spaces: A geography of gender and sexuality. London: Routledge.

Jackson, S., \& Scott, S. (2003). Whatever happened to feminist critiques of monogamy? In H. Graham, A. Kaloski, A. Neilson, \& E. Robertson (Eds.), The feminist seventies (pp. 27-42). York: Raw Nerve Books.

Jeffreys, S. (1999). Bisexual politics: A superior form of feminism? Women's Studies International Forum, 22(3), 273-85. doi:10.1016/S0277-5395(99)00020-5

Kaplan, R. (1992). Compulsory heterosexuality and the bisexual existence: Toward a bisexual feminist understanding of heterosexism. In E.R. Weise (Ed.), Closer to home: Bisexuality and feminism (pp. 269-80). Seattle, WA: Seal Press.

Klesse,C.(2005).Bisexualwomen,non-monogamy, and differentialistanti-promiscuity discourses. Sexualities, 8(4), 445-64. doi: 10.1177/1363460705056620.

Klesse, C. (2018). Toward a genealogy of a discourse on women's erotic autonomy: Feminist and queer-feminist critiques of monogamy. Signs. Journal of Women in Culture and Society, 44(1), 205-231. doi: 10.1086/698283

Leeds Revolutionary Feminist Group (1981). Love your enemy? The debate between heterosexual feminism and political lesbianism. Leeds: Onlywomen Press Collective.

Lynch, I., \& Maree, D.J.F. (2013). Negotiating heteronormativity: Exploring South African bisexual women's constructions of marriage and family. Feminism and Psychology, 23(4), 459-77. doi: 10.1177/0959353513480019

Mackenzie, C. (2014). Three dimensions of autonomy: A relational analysis. In A. Veltman \& M. Piper (Eds.), Autonomy, oppression, and gender (pp. 15-40). New York: Oxford University Press.

Mackenzie, C., \& Stoljar, N. (1999). Introduction. In C. Mackenzie \& N. Stoljar (Eds.), Relational autonomy: Feminist perspectives on autonomy, agency, and the social self (pp. 3-34). Oxford: Oxford University Press.

McNay, L. (2000). Gender and agency. Oxford: Blackwell.

Monro, S. (2015). Bisexuality: Identities, politics, and theories. Basingstoke: Palgrave Macmillan. doi:10.1057/9781137007315 
Murray, A.S. (1995). Forsaking all others: A bifeminist discussion of compulsory monogamy. In N. Tucker, L. Highleyman, \& R. Kaplan (Eds.), Bisexual politics, theories, queries and visions (pp. 293-304). New York: Harrington Park Press.

Plummer, K. (1995). Telling sexual stories: Power, change and social worlds. London: Routledge.

Queen, C. (1995). Sexual diversity and bisexual identity. In N. Tucker, L. Highleyman, \& R. Kaplan (Eds.), Bisexual politics, theories, queries and visions (pp. 151-60). New York: Harrington Park Press.

Rich, A. 1983. Compulsory heterosexuality and lesbian existence. In A. Snitow, C. Stansell, \& S. Thompson (Eds.), Desire: The politics of sexuality (pp. 212-41). London: Virago.

Richardson, D., McLaughlin, J., \& Casey, M.E. (Eds.). (2006). Intersections between feminist and queer theory. Basingstoke: Palgrave Macmillan.

Ritchie, A., \& Barker, M. (2007). Hot bi babes and feminist families: Polyamorous women speak out. Lesbian and Gay Psychology Review, 8(2), 141-51.

Robinson, M. (2013). Polyamory and monogamy as strategic identities. Journal of Bisexuality 13(1), 21-38. doi:10.1080/15299716.2013.755731

Robinson, V. (1997). My baby just cares for me: Feminism, heterosexuality and non-monogamy. Journal of Gender Studies 6(2), 143-57. doi: 10.1080/ 09589236.1997.9960678

Rodriguez Rust, P.C. (2000). The biology, psychology, sociology, and sexuality of bisexuality. In P.C. Rodriguez Rust (Ed.), Bisexuality in the United States: A social science reader (pp. 403-70). New York: Columbia University Press.

Rosa, B. (1994). Anti-monogamy: a radical challenge to compulsory heterosexuality. In G. Griffin, M. Hester, S. Rai, \& S. Roseneil (Eds.), Stirring it: Challenges for feminism (pp. 107-20). London: Taylor and Francis.

Rubin, G. (1992). Thinking sex: Notes for a radical theory of the politics of sexuality. In C.S. Vance (Ed.), Pleasure and danger (pp. 267-319). London: Pandora.

Stelboum, J.P. (1999). Patriarchal monogamy. In M. Munson \& J.P. Stelboum (Eds.), The lesbian polyamory reader: Open relationships, non-monogamy, and casual sex (pp. 39-46). New York: Harrington Park Press.

Udis-Kessler, A. (1992). Closer to home: Bisexual feminism and the transformation of hetero/sexism. In E.R. Weise (Ed.), Closer to home: Bisexuality and feminism (pp. 183-201). Seattle, WA: Seal Press.

Udis-Kessler, A. (1996). Identity/politics: Historical sources of the bisexual movement. In B. Beemyn, \& M. Eliason (Eds.), Queer Studies (pp. 52-63). New York: New York University Press.

Veltman, A., \& Piper, M. (2014). Introduction. In A. Veltman, \& M. Piper (Eds.), Autonomy, oppression, and gender (pp. 1-11). New York: Oxford University Press.

Vernallis, K. (1999). Bisexual monogamy: Twice the temptation but half the fun? Journal of Social Philosophy, 30(3), 347-68.

Walters, D.S. (2016). Special issue: Pleasure and danger: Sexual freedom and feminism in the Twenty-First Century. Signs. Journal of Women in Culture and Society, 42(1).

Wandrei, K.E. (2019). "Sleeping with the enemy": Non-monogamy and 1970s lesbian-feminists. Sexualities, 22(4), 489-506. doi: 10.1177/1363460717750074

Weise, E.R. (1992). Introduction. In E.R. Weise (Ed.), Closer to home: Bisexuality and feminism, (pp. ix-xv). Seattle, WA: Seal Press. 


\section{Christian Klesse}

Willey, A. (2016). Undoing monogamy. The politics of science and the possibilities of biology. Durham, NC: Duke University Press.

Yoshino, K. (2000). The epistemic contract of bisexual erasure. Stanford Law Review, 52(2), 353-461.

Young, S. (1997). Dichotomies and displacement: Bisexuality in queer theory and politics. In S. Phelan (Ed.), Playing with fire: Queer politics, queer theories (pp. 51-74). New York: Routledge. 